\title{
The apparent size of entoptic after-images
}

Thirty-four male Ss made size and distance estimates of an after-image observed with closed eyes. Size estimates showed small variability, but distance estimates were highly inconsistent. To account for the consistent size estimates it is tentatively proposed that although the subjective impression is of boundless space, with eyes closed the sensory system acts as if the eyes are fixated at a finite rather than infinite distance.

Gibson (1950, p. 32) asserts that if "one observes an after-image against one's closed eyes or in absolute darkness, or against the cloudless sky it seems to float in what might be called an indefinite space. It does not seem to have any precise distance and likewise no precise size." Whilst Gibson's statement has an intuitive appeal, casual observations made during a study of Emmert's law gave the author the impression that after-images may have a definite appearance of size even when viewed with the eyes closed。

The present study was designed to see if Ss can make estimates of the apparent size and distance of an afterimage when their eyes are closed and to see if these estimates are systematically related to properties of the inducing stimulus.

\section{Subjects}

Ss were 34 male students from an introductory psychology class who were screened on the Bausch and Lomb Orthorater and had an equivalent of $20 / 20$ vision in their right eye.

\section{Apparatus}

The after-image including stimulus was a circle of $2-1 / 4$ in. diameter lighted by a $24 \vee$ Grimes C-3A inter-aircraft control lamp fitted with a green filter. The lamp was located at a distance of $45 \mathrm{in}$. from $\mathrm{S}$. Procedure

Ss were tested individually and when seated were read the following instructions verbatim: "In this experiment I want you to use your right eye. Could you place this eye patch over your left eye?... Now will you look at the center of this circle (E points). I am going to shine a green light in your eye for a few seconds. It may feel a little unpleasant but it will not hurt your eye. (Light on for $30 \mathrm{sec}$.) Now close your eye (15 sec. pause). Can you see a green after-image? What is the diameter of the circle? How far away from you does it seem to be? $(5 \mathrm{~min}$. rest, during which time $\mathrm{S}$ took a color vision test). Now I want you to look at the center of the circle whilst I turn the light on again. (Light on $30 \mathrm{sec}$.) Now close your eye. (15 sec. pause.) Now will you ignore the after-image and tell me the diameter of the green light you were just looking at when your eyes were open. How far away from you did it seem to be?"

\section{Results and Discussion}

All estimates of diameter of the after-image were given in fractions of an inch, "one-quarter of an inch" being the most common response $(N=21)$. The mean estimate of diameter was 0.27 in. $(\sigma=0.13)$. Distance responses for the after-image were made either in inches $(\mathrm{N}=16)$ or feet $(\mathrm{N}=18)$. As this is a clear difference in response, separate analyses of data were made for "inches" (I) and "feet" (F) distance responses. Table 1 lists the means and standard deviations for size (diam.) and distance for both groups. A t-test between the mean diameters of after-images for groups I and $F$ was not significant $(t=1.00, d f=32)$. Thus the present results indicate that naive $S s$ can consistently estimate the apparent size of the after-image although the estimates of apparent distance fall into two distinct clusters. This raises the question as to how these results may be related to properties of the inducing stimulus.

The mean estimate of diameter of the after-image inducing stimulus was $2.43 \mathrm{in} .(\sigma=0.58)$ and the mean distance away was $3.74 \mathrm{ft}$. $(\sigma=0.73)$. As the real diameter was $2.25 \mathrm{in}$. and the real distance $3.75 \mathrm{ft}$., these estimates corresponded closely to the veridical values. From these results it is clear that $\mathrm{Ss}$ were not making estimates of the size of the after-image by giving the apparent diameter of the inducing stimulus they had just observed. For group F a t-test (related samples) comparing the means of after-image distance and means of inducing stimulus distance estimates was not significant $(t=1.13, d f=17)$. Thus although size estimates were not influenced directly by the apparent size of the inducing stimulus, just over half the distance estimates were not significantly different from the apparent distance of the inducing stimulus.

The ratio of the distance of the inducing stimulus to its diameter is $20: 1$. Using apparent estimates the mean ratio is 18.32:1 $(\sigma=4.10)$. For group I the mean ratio is $15.02: 1 \quad(\sigma=15.31)$ and for group $F$ the mean ratio is 452.66:I $(\sigma=890.60)$. Thus Ss' estimates do not conform to Emmert's law of apparent sizes (Price, 1961).

The hypothesis that estimates are only reflecting habitual response tendencies seems unlikely in view of the consistency with which Ss made size estimates.

Table 1. Mean and standard deviations of diameter and distance estimates for groups $I$ and $F$.

\begin{tabular}{cccccc} 
& \multicolumn{2}{c}{$\begin{array}{c}\text { Group I }(N=16) \\
\bar{x}\end{array}$} & \multicolumn{2}{c}{ Group $F(N=18)$} \\
\hline Diameter & $0.29 \mathrm{in.}$ & 0.16 & & $0.25 \mathrm{in.}$ & 0.10 \\
Distance & $3.45 \mathrm{in}$. & 2.66 & $6.17 \mathrm{ft}$. & 2.85 \\
\hline
\end{tabular}


Nevertheless in order to obtain some data on response tendencies, 66 male students were given the following instructions: "I want you to close your eyes and imagine you see a disk. (Pause.) Now estimate its diameter. Keep your eyes closed. Now estimate how far away from you this imaginary disk appears to be." Fifty-three Ss gave estimates of diameter in inches, the mean value being 6.06 in. $(\sigma=4.33)$. With the exception of $8 \mathrm{Ss}$, distance estimates were in feet, the mean value being $11.21 \mathrm{ft} .(\sigma=24.37)$. The other $13 \mathrm{Ss}$ gave estimates of both diameter and distance in feet. Hence it appears that responses in the presence of the after-image were not a simple reflection of habitual response tendencies.

The following is proposed as a tentative and speculative explanation for the relatively consistent size estimates and wide range of distance estimates obtained: With closed eyes the visual scene lacks apparent depth and has the appearance of "infinite" or unbounded space. Nevertheless it could be assumed that in this state the eyes are fixated at some distance, but in the absence of "psychological" cues the S's perceptual system may process information about the after-image as if it were projected at the plane corresponding to the fixated distance. If it is further assumed that the fixated distance for closed eyes is a relatively stable property of the sensory system then consistency in size estimates from $S$ to $S$ is explicable. On these assumptions the distance at which the eye is fixated could be extracted from the data assuming Emmert's law to hold for "real" rather than apparent distance (Young 1951). For the present inducing stimulus a diameter estimate of $1 / 4$ in. could be expected from a projection plane at 5 in. Further research is in progress to test this inference.

\section{References}

Gibson, J. J. The perception of the visual world. Boston: Houghton Mifflin, 1950.

Price, G. R. An Emmert's law of apparent sizes. Psychol. Rec., $1961,11,145-151$

Young, F. A. Concerning Emmert's law. Amer. J. Psychol., 1951, $64,124-128$.

\section{Note}

1. The author is grateful to Sherman L. Guth for many helpful suggestions in the preparation of this paper. 